\title{
Queenscliff revisited: evaluation of a community screening campaign for hypertension
}

\author{
DAVID CHRISTIE \\ From the Department of Community Health, University of Melbourne, Melbourne, Victoria, Australia
}

SUMMARY A screening campaign for high blood pressure was carried out in the Victorian township of Queenscliff in 1975. In late 1981, 99\% of the population screened was identified as being alive or dead and, in the latter case, the date of death was ascertained. Survival curve analysis showed a significantly worse prognosis for those subjects diagnosed as hypertensive, despite a high prevalence of treatment and a specific screening programme. It is suggested that the results of controlled trials do not translate easily to uncontrolled situations and that mass-screening campaigns may not be an effective way of intervening in countries with more open medical systems.

High blood pressure is well recognised as a personal characteristic, predisposing the individual to premature death. Furthermore, the condition is easily recognised by a non-invasive technique and is amenable to intervention by effective drug treatment. Hypertension is one of the few conditions that fulfil all the criteria for detection by mass-screening ${ }^{1}$; a relatively recent issue of a journal concerned with preventive medicine contained 265 abstracts, most of which were concerned with screening programmes for hypertension. ${ }^{2}$

In 1975, in the Victorian township of Queenscliff, a mass-screening campaign seeking people with high blood pressure was carried out. The present study, by follow-up of the population assesses the present risks of hypertension and evaluates the screening campaign.

\section{Methods}

The methods and results of the screening programme have been previously reported, ${ }^{3}$ and the exercise was preceded by consultations with all the doctors practising in the area. The target population consisted of all adults residing permanently in the town and was defined from the electoral roll, extensively updated by fieldwork. The overall response rate was $75 \%$ (1456 subjects), but references to the census population suggested that the 1124 subjects aged 40 or over represented almost $90 \%$ of the residents of this age group.

Each subject attending completed a self-administered questionnaire and then had their blood pressure recorded with a London School of Hygiene sphygmomanometer. Standard cuff size was
$22 \times 12 \mathrm{~cm}$, diastolic pressure was taken as phase 5 , or disappearance of sounds, and all three observers were trained with tapes from the London School of Hygiene. At this first visit two recordings were made in succession and the mean reported. Those subjects in whom the mean diastolic pressure was $100 \mathrm{~mm}$ or more were requested to return for a repeat pair of blood pressure measurements. Where the grand mean was $100 \mathrm{~mm}$ diastolic or more, the subject was advised to attend his named doctor, who was notified independently. Of 58 subjects so referred, inquiry three months later showed that $51(88 \%)$ had in fact visited their doctor.

The screening campaign was carried out in May 1975, and during the three months August to November 1981 an attempt was made to identify positively each of the 1124 subjects aged 40 and over who had attended the survey. The method used was that of "door-knocking" and if the subject was not available statements from spouse, siblings, or close relatives only were accepted as indicating whether the subject was alive or dead. Under the latter circumstances date of death was recorded. All but 12 subjects could be so identified ( $99 \%$ success) and these were regarded as still being alive for purposes of analysis. Altogether 160 subjects had died over the 6.51 years since the screening campaign.

For the survival curve analysis, hypertension was defined as a systolic pressure of $160 \mathrm{~mm}$ or more or a diastolic pressure of $95 \mathrm{~mm} \mathrm{Hg}$ or more, or both ${ }^{4}$; in addition a subject taking drugs for high blood pressure was classified as "hypertensive" regardless of the sphygmomanometer reading. Analysis was carried out on the VAX computer, using a program developed by Pike, Howard, Smith, and Casagranda 
of the Department of Health and Social Security Cancer Epidemiology and Clinical Trials Unit, Oxford. Significance testing of the survival curves was by the log rank test after stratification on sex and 10-year age groups. Age and sex-adjusted relative risks were calculated from Queenscliff, and from the Framingham data, ${ }^{5}$ by the method described by Pike and Smith (personal communication, 1982). For the latter comparison the definition of hypertension in the Queenscliff data was changed (essentially removing the lower reading sphygmomanometer group, who were receiving treatment); because of smaller numbers the lower age range was collapsed to 40-54, as compared with the Framingham groups 35-44 and 45-54. Otherwise, the definitions of hypertension were comparable.

\section{Results}

Queenscliff is a fishing port, whose proximity to the city of Melbourne has made it a desirable retirement haven for professionals and senior executives. Consequently the social class structure is skewed to the high side, which is reflected in the standardised mortality ratio of the observed cohort being 78 .

The prevalence of hypertension $(165 \mathrm{~mm}$ systolic or $95 \mathrm{~mm} \mathrm{Hg}$ diastolic, or both) in this population, by age and sex, was shown to be almost identical to that described from the US National Health Survey, 1960-2. ${ }^{3}$ Table 1 shows the age and sex distribution of subjects, together with the prevalence of antihypertensive treatment. Queenscliff is a well-doctored area and this, together with the publicity to the profession on the benefits of treating lower levels of blood pressure, shows the relatively high prevalence of treatment.

In the figure the survival over the 6.51 years after the screening survey of those people with systolic pressure of $160 \mathrm{~mm}+$ or $95 \mathrm{~mm}+$ diastolic, or both, or receiving drugs for hypertension is compared with the survival of non-hypertensive subjects. The 31 subjects who did not respond to the question on drug treatment for hypertension are here regarded as not receiving such treatment. The difference in survival was quite pronounced and the log rank test, working on fortnightly periods and after stratification for age and sex, indicates a level of statistical significance with $\mathrm{p}<0.0001$

In the absence of a contemporary control group the data from the Framingham Studys was used to calculate age and sex-adjusted relative risk with $95 \%$ confidence limits. In table 2 this risk is compared with that calculated from the Queenscliff data using the same definition of hypertension. The difference is trivial.

Table 2 Deaths, person-years at risk, and age and sex-adjusted relative risks in the Queenscliff and Framingham ${ }^{5}$ populations. (Ages up to 75)

\begin{tabular}{|c|c|c|c|c|c|}
\hline & \multicolumn{2}{|c|}{ Not hypertensive } & \multicolumn{2}{|c|}{ Hypertensive } & \multirow{2}{*}{$\begin{array}{l}\text { Relative risk } \\
\text { (adjusted to sex } \\
\text { and 10-year } \\
\text { age strata) }\end{array}$} \\
\hline & Deaths & $\begin{array}{l}\text { Person } \\
\text { years }\end{array}$ & Deaths & $\begin{array}{l}\text { Person } \\
\text { years }\end{array}$ & \\
\hline Queenscliff* & 58 & 4478 & 38 & 1515 & $\begin{array}{l}1 \cdot 71 \\
(1 \cdot 13-2 \cdot 57)\end{array}$ \\
\hline Framingham* & 430 & 61930 & 227 & 14024 & $\begin{array}{l}1.76 \\
(1.50-2.08)\end{array}$ \\
\hline
\end{tabular}

*Chi-square for heterogeneity among sex and age-strata non-significant.

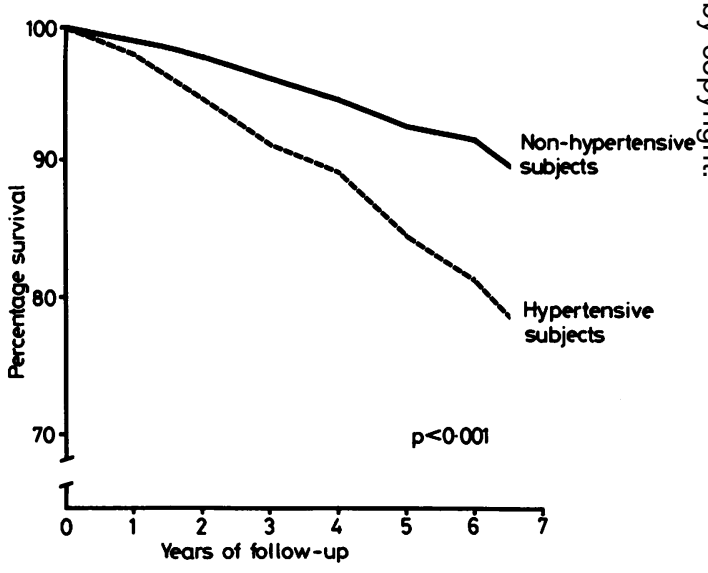

Survival curves in hypertensive and non-hypertensive subjects (definition in text). Log rank test of significance after stratification on sex and 10-year age groups.

Table 1 Members of the study population, by age and sex. (Percentage of subjects currently receiving antihypertensive medication in parentheses)

\begin{tabular}{|c|c|c|c|c|c|c|}
\hline & $40-49$ & $50-59$ & $60-69$ & $70-79$ & $\geq 80$ & All ages \\
\hline Men & $\begin{array}{c}73 \\
(9 \cdot 6 \%)\end{array}$ & $\begin{array}{l}99 \\
(12 \cdot 1 \%)\end{array}$ & $\begin{array}{l}159 \\
(17 \cdot 2 \%)\end{array}$ & $\begin{array}{l}117 \\
(17.9 \%)\end{array}$ & $\begin{array}{l}26 \\
(19 \cdot 2 \%)\end{array}$ & $\begin{array}{l}474 \\
(15 \cdot 0 \%)\end{array}$ \\
\hline Women & $\begin{array}{c}92 \\
(9.8 \%)\end{array}$ & $\begin{array}{l}146 \\
(15 \cdot 1 \%)\end{array}$ & $\begin{array}{l}223 \\
(25 \cdot 6 \%)\end{array}$ & $\begin{array}{l}123 \\
(24 \cdot 4 \%)\end{array}$ & $\begin{array}{l}35 \\
(28 \cdot 6 \%)\end{array}$ & $\begin{array}{l}619 \\
(20 \cdot 8 \%)\end{array}$ \\
\hline Total & $\begin{array}{l}165 \\
(9.7 \%)\end{array}$ & $\begin{array}{l}245 \\
(13.9 \%)\end{array}$ & $\begin{array}{l}382 \\
(21 \cdot 7 \%)\end{array}$ & $\begin{array}{l}240 \\
(21 \cdot 3 \%)\end{array}$ & $\begin{array}{l}61 \\
(24 \cdot 6 \%)\end{array}$ & $\begin{array}{l}1093^{*} \\
(18.2 \%)\end{array}$ \\
\hline
\end{tabular}

*Thirty-one subjects failed to record whether receiving antihypertensive treatment or not. 


\section{Discussion}

The purpose of the screening programme was not only to seek and.refer for treatment previously undiagnosed hypertensive subjects but also to encourage those already receiving such treatment. Follow-up, well over six years later, showed a strong mortality differential working against the hypertensive subjects. The importance of hypertension as a risk factor for premature death is thus emphasised, but doubts arise as to the effectiveness of the screening programme and, indeed, as to the value of the reported high prevalence of treatment.

Firmly based on the results of carefully controlled clinical trials, ${ }^{67}$ the treatment of individuals with asymptomatic hypertension has become an important part of the physician's task. Since the condition is asymptomatic, mass screening of communities seems a logical development. Reader ${ }^{8}$ stated that "an organised public health programme for the control of hypertensive disease offers one of the most rewarding opportunities of our time ...." Judged solely by process criteria, the Queenscliff programme was entirely successful; the critical question is whether the programme was effective in the longer run at reducing the probability of death in those people suffering from the condition in question.

In the absence of a contemporary control community, it was thought necessary to resort to "historical controls"- namely, the data collected in Framingham, Massachusetts, 20 years ago. There are many objections to the use of such controls but, in the present context, between-country differences are likely to be of much less importance than the time difference. Over the decades in question, mortality from cerebrovascular disease has been steadily falling and that from coronary heart disease has at least stabilised. Consequently, any expected change in the relative risk for hypertension must be towards its reduction. That the relative risk in Queenscliff was not particularly different from that of the Framingham population leads inevitably to the conclusion that the screening programme at Queenscliff could not have been very effective.

In a controlled clinical trial the organisers usually manage all aspects of the treatment themselves and this management is along predetermined lines. For a community screening programme to be followed up by such an integrated approach, as has been suggested as the ideal, ${ }^{9}$ a degree of control is required over medical services that does not exist in Australia, or even in the British system. In reality doctors prescribe what they will to patients who take the drugs as they see fit. Since drug treatment for hypertension is likely to consume more and more of the health budget, it would seem urgent to determine the success or otherwise with which results from tightly controlled interventions translate to the more open scene.

\section{References}

${ }^{1}$ Wilson JMG, Jungner G. Principles and practice of screening for disease. Geneva: World Health Organisation, 1968. (Public Health Paper No 34.)

${ }^{2}$ Abstracts. Fifth national conference on high blood pressure control. Prev Med 1979, 8: 119-253.

${ }^{3}$ Christie D, McPherson L, Vivian V. The Queenscliff study: a community screening programme for hypertension. Med J Aust 1976, 2: 678-80.

${ }^{4}$ World Health Organisation. Arterial hypertension and ischaemic heart disease. Geneva: World Health Organisation, 1962, (Technical Report Series, No 231.)

${ }^{5}$ Kannel WB, Gordon T, eds. The Framingham study: an epidemiological investigation of cardiovascular disease. Section 26. Washington: US Government Printing Office, 1970.

${ }^{6}$ Veterans Administration Cooperative Study Group on Antihypertensive Agents II. Results in patients with diastolic pressures averaging $90 \mathrm{~mm}$ through $114 \mathrm{~mm}$ Hg. JAMA 1970; 213: 1143-52.

${ }^{7}$ Management Committee. The Australian therapeutic trial in mild hypertension. Lancet 1980; i: 1261 .

${ }^{8}$ Reader R. In: Freis ED. ed. Screening and community control of hypertension in the treatment of hypertension. Lancaster: MTP Press Ltd. 1978.

${ }^{9}$ Hypertension Study Group. Guidelines for the detection, diagnosis and management of hypertensive populations. Circulation 1971; 44: A263-72. 